\title{
General anesthetic management of Prader-Willi syndrome patient undergoing bariatric surgery: a case report
}

\author{
Lijnzaat L., Rodrigues J., Pelicano Paulos J., Romão C., Silva Pinto J.M., Fragata I.. \\ Department of Anesthesiology, Centro Hospitalar de Lisboa Central, Lisbon, Portugal
}

\section{BACKGROUND}

Prader-Willi syndrome (PWS) is a rare genetic disorder with severe hypotonia during the first years, hyperphagia with a risk of morbid obesity, intellectual and behaviour impairment. Patients can also have sleep apnea, high pain threshold, temperature instability, hypothyroidism and growth hormone deficiency. Forehead is narrow, hands and feet small, height short and skin color is light. ${ }^{1,2,3}$ Anaesthetic concerns of PWS include morbid obesity and sleep apnea, difficult intravenous (IV) access and airway management, risk for perioperative respiratory failure, primary myocardial involvement, aggressive behaviour, convulsions, and disturbances in thermoregulation as well as glucose intolerance. ${ }^{2,3}$

\section{CASE REPORT}

17-year-old PWS female patient, with a BMI of 89 $\mathrm{kg} / \mathrm{m} 2$, who underwent biliopancreatic diversion with duodenal switch. The patient had already underwent surgery 12 years ago (amygdalectomy and adenoidectomy), and the only information we had is that she went post-operatively to an intensive care unit. A CMAC video laryngoscope was the first option for intubation, and a total intravenous anesthesia was the choice for this case. Intubation was performed successfully after 3 attempts by the same anesthesiologist (with more than 10 years of experience). Due to the difficulty with the insertion of an IV access, it was decided to place a central venous line and also an arterial line for monitoring. The surgery was uneventful. The patient was transferred to the intensive care unit, where extubation was performed after a few hours.

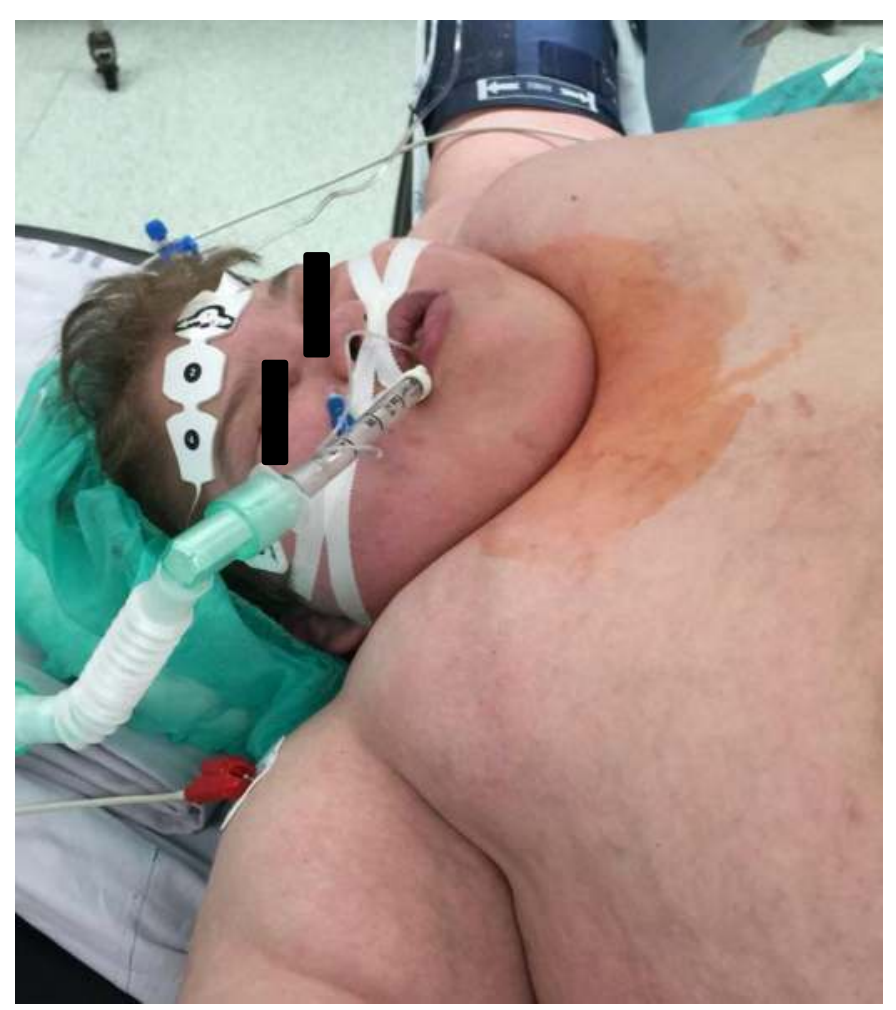

\section{DISCUSSION}

PWS patients can now reach the $5^{\text {th }}$ decade if extreme obesity is avoided $^{1}$. Bariatric surgery can be performed for weight control. ${ }^{2}$ Anesthesia is certainly a challenge in these cases. Airway management can be challenging, as well as the IV access. There' $\mathrm{s}$ also a risk of postoperative complications that the anesthesiologist should be aware.

\section{CONCLUSION}

Patients like this one are a challenge for the anesthesiologist, and planification is the most important thing to avoid complications. This will help to maintain a calm environment in the operating room, which will help the patient and all the staff.

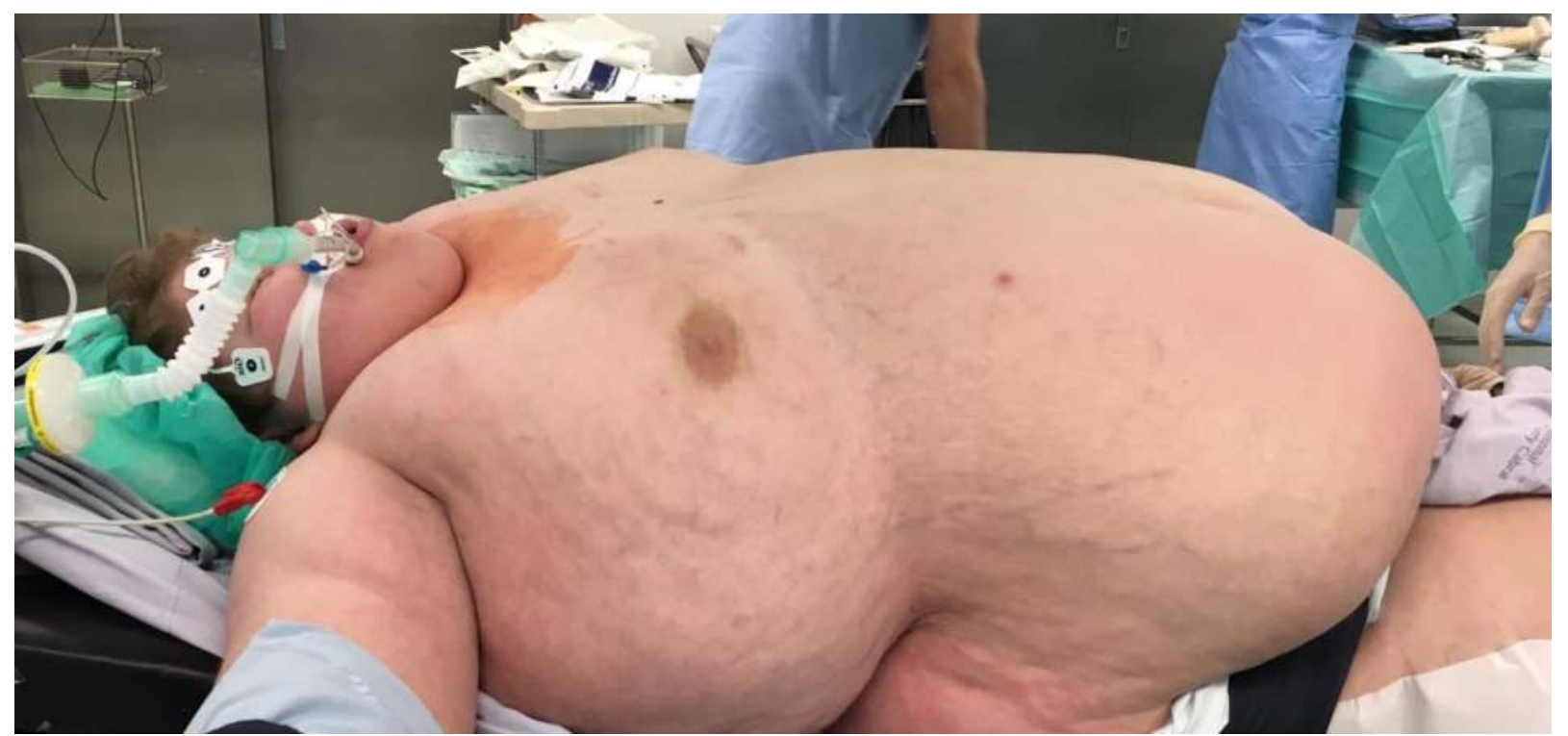

References:

1. Irizarry KA, Miller M, Freemark M, et al. Advances in Pediatrics, 2016 Aug, 63

(1): 47-77

2. Alqahtani AR, Elahmedi MO, Awadh R. Al Qahtani AR et al.Surgery for Obesity and Related Diseases, 2016 Jan, 12(1): 100-110

3. Lee JY, Cho KR, Kim MH, et al. Korean J Anesthesiol, 2012 Jul; 63(1): 85-86. 